\title{
Ensino integrado das ciências, um presente envenenado
}

\author{
ANA PAULA DA SILVA CORREIA E JOSÉ RODRIGUES RIBEIROP
}

$\mathrm{N}$ DECORRER DO PROCESSO DA REVISĀO Participada do Currículo, que o governo Guterres lançou a partir de Fevereiro de 1997, foi apresentada como grande inovação pedagógica a integração numa única disciplina das dimensões teórica e prática do ensino das ciências, o chamado ensino integrado das ciências.

Para levar a água ao seu moinho, o Departamento do Ensino Secundário, entẫo presidido por Domingos Fernandes, começou por promover a auscultação das escolas e dos parceiros educativos através da reflexão sobre um certo número de documentos de trabalho. Estes estavam elaborados num "eduquês" tão hermético que, para muitos dos interlocutores, só tarde de mais se tornaram evidentes as reais intenções do Ministério. (Atente-se que em momento algum era questionada a continuação das Técnicas Laboratoriais!?

A seguir, tiveram início os auto-intitulados Encontros do Secundário, que consistiram numa espécie de sessões de esclarecimento, realizadas em escolas das capitais de distrito, em que os responsáveis governamentais transmitiram a plateias de professores criteriosamente seleccionadas a sua leitura dos resultados dos inquéritos e recolheram as opiniões dos participantes. Esta metodologia, pela série de filtros que comporta, vai abafar as vozes individuais. disse (e bem) um dos participantes nesses Encontros do Secundário

Toda esta preparação culminou na elaboração da proposta de Revisão Curri- cular em que - contrariando a opinião expressa pela SPQ e pela SPF, e sem qualquer estudo minimamente credivel da experiência da reforma ainda em vigor - eram extintas as Técnicas Laboratoriais e demais disciplinas da formação técnica. Recentemente, com o governo de Durão Barroso, a aplicação da revisão curricular foi suspensa por um ano, mas (como é do conhecimento geral) as alteraçōes introduzidas pioraram ainda mais a situação.

Sabemos que há ainda quem pense que a nova disciplina de Física e Química $\left(10^{\circ}-11^{\circ}\right.$ anos) assegura a integração das componentes teórica e experimental e que, por isso, substituirá com vantagem as velhas CFQ e TLQ. Essa perspectiva não resiste, porém, a um confronto com a realidade, na medida em que:

a) Os anteriores programas de CFQ (da Reforma Roberto Carneiro) já previam a realização de actividades experimentais relacionadas com os conteúdos da disciplina, mas estas não eram concretizadas, não apenas por falta de tempo (em muitas escolas, nem sequer os conteúdos teóricos sāo leccionados na sua totalidade) mas principalmente porque não é fácil ao mesmo professor conjugar conteúdos teóricos com trabalhos práticos, numa mesma disciplina.

b) Nesses programas, estavam mesmo destinadas duas horas semanais para que os alunos tivessem aulas no Laboratório, mas toda a gente sabe que a realidade tem sido bem dife- rente e que só muito episodicamente há aulas experimentais de CFQ do $10^{\circ}$ e $11^{\circ}$ anos. Está igualmente escrito nos programas ainda em vigor que a execução das actividades experimentais será tida em conta na avaliação dos alunos, mas duvidamos que tal seja aplicado em alguma escola portuguesa. Ou seja, a prática de vários anos já comprovou, sem margem para dúvidas, que não é viável a integração das componentes teórica e experimental do currículo. Porque haveria de funcionar agora?

c) Na generalidade das escolas, é unicamente nas Técnicas Laboratoriais (dado serem disciplinas predominantemente experimentais) que existe disponibilidade de tempo para, cumprindo o programa, os alunos levarem a cabo trabalhos práticos de laboratório - e não meras demonstrações efectuadas pelo professor sendo as suas competências para o trabalho experimental tidas em conta na avaliação. Daí que, de acordo com o Livro Branco da Física e da Química, 77\% dos professores sejam favoráveis às Técnicas Laboratoriais, contra $13 \%$ de opiniões contrárias.

d) Por outro lado e ao contrário do afirmado na revisão curricular, nos programas da nova disciplina de Física e Química as actividades experimentais surgem completamente deslocadas dos conteúdos teóricos da disciplina, mais parecendo que foram aí inseridas para justificar a eliminação das Técnicas Laboratoriais. Nessas condições, as actividades experi- 
Carga horária semanal (em minutos) das disciplinas de Ciências no curso geral

\begin{tabular}{llllll}
\hline & $10^{\circ}$ ANO & $11^{\circ}$ ANO & $12^{\circ}$ ANO & TOTAL & Variação em relação a 1990 \\
\hline Reforma Roberto Carneiro (1990) & 700 & 700 & 800 & $\mathbf{2 2 0 0}$ & \\
"Cortes" de Manuela F. Leite (1995) & 700 & 700 & 650 & 2050 & $-7 \%$ \\
Revisão PS (2000) & 540 & 540 & 540 & 1620 & $-26 \%$ \\
Revisão PSD (2002) & 270 & 540 & 540 & 1350 & $-39 \%$ \\
\hline
\end{tabular}

mentais, mesmo que pudessem ser concretizadas, em nada seriam benéficas para a leccionação da disciplina.

e) Quer a revisão de Marçal Grilo, quer a versão de David Justino, contemplam uma diminuição acentuada do tempo destinado às ciências na Reforma, já afectado pela eliminação de uma das disciplinas técnicas do $12^{\circ}$ ano quando Manuela Ferreira Leite ocupou a pasta da Educação. São por isso previsíveis grandes dificuldades para a leccionação dos conteúdos, uma vez que os programas continuam demasiado extensos.

f) Face a todos estes constrangimentos, não são necessárias grandes cogitações para antever que a componente prática será inevitavelmente sacrificada na nova disciplina de Física e Química. Tanto mais que a disciplina irá ser sujeita a um exame final, que (evidentemente) terá a forma de prova escrita e não de prova prática de ciência experimental. O que não é avaliado, tende a não ser ensinado.

Por todas estas razões, o "ensino integrado das ciências" mais não é que o fim do ensino experimental da Química, da Física e das demais ciências nas nossas escolas secundárias. Importa por isso que os professores se mobilizem e unam a sua voz à proposta da $S P Q$ e estejam especialmente atentos e actuantes face a qualquer tentativa de, a pretexto da aplicação dos novos programas já em 2003/2004, ser introduzido subrepticiamente o ensino integrado.

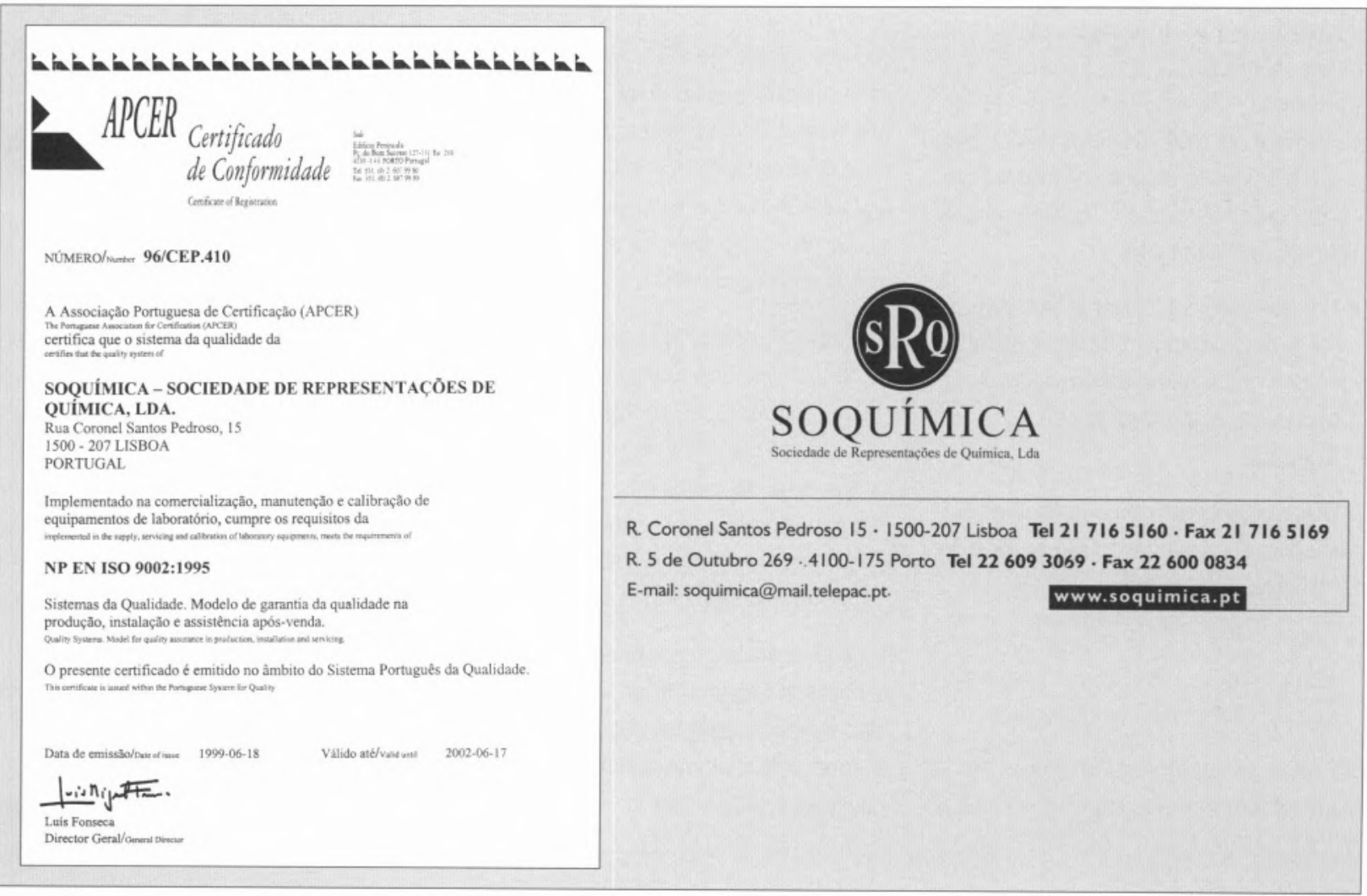

